\title{
Los derechos de autor en los medios ciberespaciales
}

\author{
José María Desantes Guanter \\ Capitán Haya 20, \\ 28020, Madrid, España.
}

\begin{abstract}
RESUMEN
El artículo aborda la problemática jurídica y legal que está empezando a producir la búsqueda de soluciones en tomo a los denominados derechos deautor. El tema se ha modificado grandemente con la aparición del ciberespacio, que, entre otras cosas, supone una concentración de medios que permiten mensajes más complejos, lo que al mismo tiempo sucita nuevos problemas en cuanto ala atribución de la titularidad del derecho de autor. ¿Qué hacer, por ejemplo con ciertos objetos que también podría proteger el derecho de autor, como la especial estructura de la expresión, la indización, el tesauro, el programa de computadora específico para elaborar una estructuray el consiguiente uso deventanas, fondos, íconos y páneles de control que componen a cada uno de estos programas?
\end{abstract}

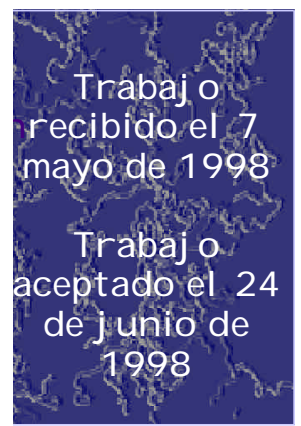

ABST RACT

COPYRIGHT IN CYPERSPACE MEDIA

José María Desantes-GuANTER

The article tackles the juridical and legal problem that the search for solutions with respect to so-called copyright is beginning to generate. The subject has undergone substantial changes with the appearance of cyberspace which, among other things, supposes a concentration of media that permit more complex messages, which at the same time presents new problems with respect to the attribution of copyright ownership. What to do, for example, with certain objects that can also be protected by copyright, such as the special structure of expression, indexing, thesaurus, the specific computer program for elaborating the structure and the consequent use of windows, backgrounds, icons, and control panels that make up each one of these programs? O ne of theinconveniences of the text is that it is written in the very specialized language of juridical technicalities which is often confusing and difficult for the layperson.

\section{INTRODUCCIÓN}

F l planteamiento de un problema o de una problemática jurídica nuevos obedece $\perp$ a que la realidad compleja, variabley progresivaal ritmo del progreso de la técnica, va dando lugar a objetos inéditos de los derechos subjetivos. En D erecho objeti- 


\section{Inestigacón Biblidtedógica V. 12 No. 25 julio/ diciembre de 1998}

vo, es el objeto lo que condiciona los derechos subjetivos, las relaciones y las situaciones jurídicas, lo que les da su matiz propio y prefigura su contenido. Y el objeto unas veces es radicalmente nuevo en su consideración jurídica, como el espacio interestelar; 0 su novedad consiste en la mistificación de objetos preexistentes que da lugar a un enteantes desconocido en el mundo o en la atención del ordenamiento jurídico local o universal. Así ocurre en el conjunto de técnicas que, por unificar su innovación, su diferente composición y su apertura a progresos incesantes se conoce con el nombre global de ciberespacio.

Los autores, incluso juristas, hablan de ciberespacio, de informática, de redes 0 autopistas de información, de digitalización del proceso informativo, etcétera. No se refieren al resultado de esos procesos que no es otra cosa que un medio de comunicación, ni lo estudian en cuanto medio informativo. Sin embargo, como ha ocurrido con la documentación, su emplazamiento como verdadero medio de comunicación que es, permite verter en él todos los principios de los media y, por un proceso de deducción, ir enriqueciendo la doctrina documentaria y, en concreto, el derecho subjetivo a la documentación y el Derecho objetivo de la Documentación. Por otra parte, la ampliación de la base empírica que se produce por tal consideración como medio, genera, por inducción, un proporcionado enriquecimiento de la teoría general de los medios. La llamada "revolución de la información" lleva consigo, como consecuencia, una "evolución del D erecho", muy anterior a la innovación de la ley positiva.

En cualquier caso, y en el momento actual, el ciberespacio produce una concurrencia de medios, fenómeno inédito sólo en cierto modo porque, desde hace tiempo, se había producido ya en pequeña escala una fenomenología nueva con los llamados medios simbióticos en los que la combinación en diferentes dosis y funciones de medios tradicionales, dan lugar a un efecto complejo que aumenta la realización eficaz del derecho natural a la información, entendiendo por información todo tipo de mensajes y no sólo los que difunden noticias. Piénsese, por ejemplo, en la simbiosis entre cine y televisión.

El proceso puramente simbiótico 0 , en ocasiones, parásito de un medio respecto a otro se ha visto, más que completado, superado por el cruce de informática y telecomunicación, lo que ha dado lugar no sólo a nuevas formas de simbiosis, sino a los llamados multimedia en los que son posibles las conjunciones de varios medios y su recíproca potenciación. Cuando esta vigorización exponencial llega al máximo, podemos afirmar que no existe sólo una conexión de los medios, sino el media por excelencia. Es decir, la facultad de actuar conjunta y unitariamente las posibilidades comunicativas de varios medios que, transformándose de manera mutua, generan medios insólitos.

Si por medio se conoce la incorporación de un mensaje a un soporte, entendido éste en un sentido amplísimo o universal, no se puede negar la calificación de medio, (todo lo nuevo y peculiar que se quiera), al resultado del ciberespacio que transporta los mensajes en soportes electrónicos. Se puede comprobar que es po- 
sible y lógica la aplicación de los principios generales que rigen los medios a los procesos de integración que dan lugar al multimedia, como globalidad, libertad, unidad, responsabilidad conjunta en el resultado, etcétera.

El ciberespacio supone, así, una concentración de medios de difusión de mensajes obtenidos tanto por técnicas cibernéticas cuanto por telecomunicacionales, electrónicas o no, que obligan a variar constantemente la expresión para adaptarse al lenguaje de los nuevos medios o meda, por emplear una expresión genérica. Bien entendido, desde el principio, que esta variación no influye en la constitución y calidad de los mensajes. Pero suscita problemas en cuanto a la atribución de la titularidad del derecho de autor sobre los mismos.

Las soluciones positivas inéditas, siempre que estén ancladas en la realidad, son posibles porque toda cuestión jurídica admite un encauzamiento conforme a un principio de justicia. Que puede ser un principio supremo, especificable en otros obtenidos por deducción del primero, dando lugar en su conjunto a la metodología conocida como Jurisprudencia de principios que ha demostrado, especialmente en la nueva morfología de cuestiones informativas inducidas por la informática, su superioridad sobre otras metodologías como la llamada Jurisprudencia de conceptos o como la Jurisprudencia de intereses, que están expuestas a perder su objetividad en aras del idealismo o del materialismo, respectivamente. En aras de la Jurisprudencia de principios se puede exponer un régimen ideal del derecho de autor aplicado al ciberespacio. Régimen no ceñido a ningún ordenamiento concreto, pero cuyas directrices están en algunos de ellos. En todo caso, como ceñidos a la justicia, pueden servir para la interpretación de las normas legales que no han previsto los problemas de los nuevos medios.

Una metodología objetiva exige, en todo caso, una cuidada terminología y una bien perfilada conceptuación de las ideas como andamios que sostengan la construcción razonada y razonable, es decir, justa, de las instituciones. Mucho más cuando éstas han sufrido distorsiones en su devenir histórico por circunstancias políticas y sociales, extrañas a su médula jurídica, que no se deben confundir con su regulación legal. Precisamente el divorcio entre una y otra -entre Derecho y Ley- es una de las modalidades peligrosamente distorsionantes que se dan con mayor frecuencia en la práctica jurídica.

Estas líneas directrices han de tomarse en cuenta cuando se trata del derecho de autor sobre el objeto global nuevo que hemos llamado ciberespacio, globalización necesaria porque sus manifestaciones son diversas y aparecen, día a día, con matices diferenciales. Matices que, en cambio, no afectan a la naturaleza del derecho autoral. Entendiendo la naturaleza como la manera de ser propia de un objeto o de una institución que legitima operativamente su fenomenología y sus efectos. Y sobre la que se funda la naturaleza jurídica que no es otra cosa que la del objeto en cuanto es tenida en cuenta por el D erecho. Si el D erecho es la realidad hecha norma, se puede diseñar un régimen del derecho de autor que, siendo justo, esté recogido en la mayor parte de los ordenamientos. 


\section{Investigaaón Biblictedóǵca V. 12 No. 25 julio/ diciembre de 1998}

\section{NATURALEZA DEL DERECHO DE AUTOR}

Ya la denominación de derecho de autor frente a la equívoca de propiedad intelectual, es una baza importante para determinar la verdadera esencia de este derecho humano, natural o fundamental que es el derecho del creador de un mensaje verbal, icónico o mixto a la creación de su significado y a la de su expresión; y a su difusión.

Nominar ya es hacer ciencia, y una acertada denominación es abrir posibilidades de avance a la ciencia. Una muestra importante de estos asertos la constituye el abandono de la denominación, jurídicamente heterodoxa, de propiedad intelectual por la quizás excesivamente neutra, de derecho de autor. El error revolucionario francés al darle el retrógrado nombre de propiedad consistió en no advertir que la vida jurídica plantea insospechadas relaciones. Con una concepción burguesa, utilizó de la tradición romana una apelación dominativa, conservadora, estática, como es la propiedad. Cuando entre el derecho de autor sobre su creación y la propiedad no hay un solo carácter tangencial posible, basta comprobar en los Códigos civiles vigentes - casi todos herederos del napoleónico, lo que evita sospechas- cuaáles son las facultades del propietario sobre sus bienes físicos para darse cuenta de que ninguna puede aplicarse al autor, salvo la facultad de disposición. Pero la facultad de disposición no forma parte del contenido interno del derecho, sino que queda fuera del mismo, como el motor es externo a la máquina que mueve. Por eso acompaña extrínsecamente no sólo al derecho de propiedad, sino a todo derecho subjetivo, salvo a aquellos derechos o facultades que, por su vinculación directa con la personalidad, son intransferibles, como la dignidad. Por eso no puede formar parte de la esencia de ningún derecho y, por tanto, del derecho de autor.

El cambio doctrinal de denominación de propiedad intelectual a derecho de autor, que cada vez se va extendiendo a las legislaciones modernas, ha supuesto mucho más que una transición terminológica. Ha descubierto no solamente lo que no es el derecho dominativo atribuido al creador intelectual, que es un derecho prohibitivo ega omes sino que ha permitido descubrir aquello que es, un derecho propter ames, lo que ha supuesto dar al derecho de autor un carácter dinámico, promotor, de servicio, al mismo tiempo que se le ha afirmado como un derecho natural del hombre más entrañado en su esencia creadora o recreadora que el derecho de propiedad que satisface ansias más o menos naturales de dominio, pero no la auténtica vocación poyética del hombre.

El derecho de autor, como todo derecho subjetivo, está constituido por un conjunto de facultades, aparte la externa de disposición, que son adyacentes a una de ellas que constituye su esencia: la facultad de difusión. Si se omite la facultad de difusión que tiene todo autor sobre su creación, las demás facultades quedan sin anclaje posible porque son absolutamente inútiles: así el derecho al nombre, al anónimo o al seudónimo; a la integridad de la obra; a su modificación; a su titulación; et- 
cétera. La peculiaridad del derecho de autor consiste en que no se trata de la facultad de difusión que tiene cualquier persona, sino en concreto, de la facultad de difusión que corresponde en exclusiva al creador y, en su caso, a los causahabientes en favor de los que él mismo disponga.

Si tenemos en cuenta que la facultad de difundir es una de las tres que constituyen el derecho a la información, según describe con acierto el artículo 19 de la D eclaración Universal de los D erechos Humanos de las Naciones Unidas, promulgada el 10 de diciembre de 1948, podemos deducir, con pleno fundamento, que el derecho de autor es una aplicación concreta del derecho a la información del que disfrutan precisamente los creadores de cualquier tipo de mensajes. Si hiciera falta alguna confirmación positiva, la encontramos en el artículo 27 de la misma D eclaración en la que se compenetran en dos párrafos las facultades de investigar y recibir de toda persona (que se desprende del primero); y la de difundir del autor (que se fija en el segundo), con las secuelas de las demás facultades que flanquean y fortifican el poder radical de difusión.

$\mathrm{Al}$ analizar cualquier ley de derecho de autor que, sea la que sea su denominación, presenta la legislación comparada, podemos comprobarlo. Esta comprobación se puede hacer tanto en las leyes de los países latinoamericanos cuanto en las de los europeos, que han venido a sustituir, en el último cuarto de siglo, a las que rigieron durante más de una centuria. La consistencia jurídica así obtenida ha hecho que el derecho de autor se haya incorporado como derecho fundamental a las constituciones más modernas, entre ellas a algunas latinoamericanas.

La cuestión tiene gran importancia teórica y práctica. Teóricamente porque ha ensanchado el horizonte doctrinal del derecho de autor resolviendo las incógnitas que se planteaban cuando se concebía dominativamente; y ha permitido manejar como normales determinados fenómenos que se consideraban excepcionales e incluso patológicos de la institución, como por ejemplo, el término temporal del derecho y el pase al, también mal nominado, dominio público. D esde el punto de vista práctico, porque ha conseguido de una manera dinámica, creativa como su objeto, progresiva, dar solución a los problemas que las nuevas técnicas informativas han planteado y seguirán planteando de modo incesante. Siempre teniendo en cuenta que el medio es el instrumento de difusión.

La equiparación del derecho de autor con el derecho a la información ha enriquecido las posibilidades de uno y otro derecho naturales y los presenta con arreglo a lo que es propio del derecho: no como conflictivos o excluyentes, sino como armónicos y complementarios, en el sentido etimológico de complemento: lo que actúa coordinada y sincrónicamente; a diferencia de suplemento: lo que actúa a falta de otra cosa que le debía preceder y, por tanto, asincrónicamente.

Esta doble dimensión teórico-práctica es una fuente de soluciones a los problemas de derecho de autor que suscitan los fenómenos ciberespaciales porque los reduce todos a la posibilidad de ser conjugados por el principio general de jus- 


\section{InveticaaónBiblidtedógica V. 12 No. 25 julio/ diciembre de 1998}

ticia que representa el derecho a la información. El derecho a la información extiende su naturalidad al derecho de autor, con lo que no sólo ofrece solución a sus problemas, sino la convicción fundada de que las soluciones son justas en cada momento y situación frente a las dudas teórico-prácticas que han surgido en los ámbitos jurídicos socializantes considerando como un abuso el derecho del autor.

\section{LA GÉNESIS COMPLEJA DEL MEN SAJE PARA LOS NUEV OS MEDIOS}

Se discute cuál es la consideración conceptual de cada una de las nuevas tecnologías. A nuestros efectos la discusión no importa porque lo que es común a todas ellas es su capacidad de difusión y, en consecuencia, el ser medio para difundir mensajes. El mensaje creado es el objeto del derecho de autor. La tecnología utilizada para proporcionar tal difusión es objeto de otro derecho de naturaleza diferente al derecho de autor que es al que, en términos generales, se conoce como propiedad industrial o derecho de marcas y patentes. No obstante, en algunos aspectos, se solapan en los ordenamientos ambos derechos, como ocurre con los derechos sobre los programas de computación.

Lo que se protege, o se debe proteger, es la creatividad, tanto en el contenido del mensaje como en la expresión del mismo, esta última cuando es necesaria para adaptarse al lenguaje del nuevo medio o cuando, por constituir un medio sofisticado o un complejo de medios o multimedia, es preciso concertar sus diferentes lenguajes para conseguir su difusión, que es lo que interesa al derecho a la información y lo que constituye esencialmente el derecho de autor.

En este sentido, no sólo se protege la originalidad, sino, en su caso, conjuntamente 0 no, la independencia de expresividad de cada mensaje dispuesto para la difusión. Las leyes positivas no protegen la creación inédita, aquello que existe sólo en la mente del autor o que permanece trasladado a soportes no aptos para la difusión, 0 en forma no difundible, como lo escrito a lápiz en un papel, por ejemplo. Lo que protege el derecho de autor es la expresión de lo creado mediante la publicación por cualquier medio, lo que supone su incorporación a gran variedad de soportes, tangibles o intangibles, actualmente en funcionamiento o que se inventen o pongan en funcionamiento en el futuro. Lo que no quiere decir que el mensaje soportado esté actual y efectivamente en poder del receptor, pero sí en condiciones actuales de ser puesto a disposición del público, como lo está un libro en los estantes de una librería o una partitura sobre el atril de un director de orquesta.

La tendencia actual, por otra parte, ha dejado de ser formalista, como lo fue hasta la mitad de este siglo; y el derecho se reconoce y la protección se presta, una vez difundido el mensaje, por la mera creación, independiente de su inscripción en registros, archivos u otros medios legales de constancia, cuyo interés estriba tan sólo en su valor probatorio iunstantum siempre salvo prueba en contrario. 
La protección del derecho de autor puede estar completada, como se ha dicho, por el derecho de propiedad industrial que, sin embargo, tiene otra naturaleza y, por tanto, se rige por distintos principios. Tampoco, a pesar de su tangencia, tienen como fundamento el derecho de autor los actos de defensa contra la competencia desleal entendidos como actos objetivamente contrarios a la buena fe. Los distintos ordenamientos nacionales y supranacionales, como el de la Unión Europea, señalan alguno de estos actos con ligeras variantes. Así, actos que creen confusión con la actividad ajena; actos de imitación que den ocasión al aprovechamiento del esfuerzo o la reputación de otros; empleo de signos distintivos ajenos o imitaciones equívocas; actos de comparación engañosa o denigrante; actos concretos de denigración de las relaciones negociantes de un tercero; actos de engaño sobre ventajas realmente ofrecidas; 0 violación del secreto industrial o empresarial que afecte a la técnica de los medios ciberespaciales. Muchos de estos actos no sólo favorecen deslealmente al medio, sino que pueden cometerse a través del mismo medio, sobre todo por los mensajes publicitarios, que tienen también su regulación muchas veces rígida.

Autor y, por tanto, titular originariamente del derecho es la persona que crea alguna obra. Esta definición válida y esclarecedora para los medios tradicionales, como el libro procedente de una sola pluma, se muestra poco indicativa cuando se trata de medios en los que el mensaje resultante se produce por la concurrencia de materiales de procedencia variada, de los que son titulares intelectuales distintas personas cuya diversidad aumenta cuando la operación de incorporarlas supone también un cierto grado de creatividad e innovación. En breves palabras, cuando el resultado final es un tetiumgenussuperior a la suma de las aportaciones parciales.

\section{LA FIGURA DEL PRODUCTOR}

Tomado del Derecho de la cinematografía, se considera al Productor como sujeto posible del derecho de autor en las relaciones que rige. El productor es la persona que coordina todo el quehacer necesario para la difusión ciberespacial de mensajes, por lo que necesita concentrar todas las facultades necesarias para integrar y disponer en los mensajes complejos: los derechos de autor de los mensajes simples y los llamados derechos afines. En concreto, se entiende por productor en la comunicación ciberespacial a la persona física o jurídica que tiene la iniciativa de informar a través de un medio de este género o de un multimedia y asume la responsabilidad de la difusión. El productor concentra todos los derechos intelectuales afluentes necesarios para ejercitar la facultad de difundir. $Y$, de acuerdo con las leyes, puede, en su caso, cederlos o transmitirlos a título oneroso o gratuito, inter vivoso motiscausa 


\section{InveticaaónBiblictedógica V. 12 No. 25 julio/ diciembre de 1998}

La titularidad del mensaje resultante viene a ser independiente de la de sus componentes; lo que no significa, ni puede jurídicamente significar, que se omita la titularidad o titularidades de estos componentes a no ser que no la tengan a efectos jurídicos. En principio, es preciso obtener la pertinente licencia que permita su utilización y las modificaciones necesarias, en su caso; y, según la autorización se haya extendido, puede ser imprescindible la identificación del titular o titulares que han contribuido a la obra susceptible de ser difundida por los nuevos medios, sean estos singulares o multimedia. Lo que dará lugar, según el modo de concurrencia de mensajes de múltiples autores, a obras en colaboración, obras colectivas, obras derivadas u obras compuestas, según los casos.

A la complejidad de estas retículas de derechos autorales que pueden producirse en los nuevos medios, hay que añadir que el productor incrementa un quidno umsimplemente recopilando creaciones de diverso origen sobre las que ejercita no sólo la facultad de difusión, sino también utiliza o, en su caso, transfiere la de reproducción o fijación de la obra en un soporte que permite su comunicación independiente - lo que la doctrina llama medios de autoprogramación, como el video 0 el CD-rom- y también la obtención de copias de todos o parte de los mensajes contenidos en ellos.

El objetivo perseguido por el productor de mensajes complejos con el fin de difundirlos por medios ciberespaciales no es la adquisición de los derechos de autor sobre todas las obras que proyecta utilizar en la elaboración de los nuevos mensajes, sino en concreto la obtención de aquellas facultades que, formando parte o integrando tales derechos, sean estrictamente necesarias para conseguir la producción pretendida. D entro de las posibilidades de obtención, se puede distinguir las diferentes categorías de objetos susceptibles de derechos de autor y, por tanto, de las facultades que lo componen, entre las que estará siempre la facultad radical de difusión.

\section{LA INTEGRACIÓN LIBRE DE MATERIALES PREEXISTENTES}

El material preexistente al mensaje complejo, merezca o no la consideración previa de mensaje, puede o no estar protegido jurídicamente por el derecho de autor, aunque tenga, en ocasiones, autor conocido. El esquema de los supuestos en que no se trate de material protegido por el derecho de autor no significa que, de su inserción en el mensaje complejo resultante, no se derive una nueva autoría intelectual digna de protección.

Aquellos supuestos en que se dé esa situación jurídica o legal eximen al productor de solicitar licencia al autor 0 a su causahabiente y de realizar el acto jurídico de transferencia de facultades. Por axioma, esto sucede cuando no hay autor; pero también en otros casos exceptuados por las leyes. En todos ellos, sin 
embargo, hay que respetar los derechos morales, jurídicamente inquebrantables, en especial el de paternidad y el de integridad.

Si no hay autor, significa que el material incorporado o a incorporar no es una creación original en su génesis intelectual 0 , al menos, en su forma de expresión. Así puede ocurrir con los meros hechos, datos, cifras e, incluso, ideas y juicios anónimos como, por ejemplo, los refranes.

Está excluida por la ley la situación de aquellas creaciones que, por el transcurso de un plazo, han pasado a dominio público. Plazo que es diferente en los distintos ordenamientos y que puede ocasionar, por esa asincronía, conflictos de D erecho internacional, si la creación y la utilización se producen en países que tengan establecido distinto plazo de protección. El mismo desamparo tiene lugar en el caso improbable, pero posible, de que la creación quede libre del derecho por abandono expreso del autor original.

Las leyes positivas suelen excluir determinados materiales dado que, aun creados por alguien, son de un interés público concreto cuya utilización no debe someterse a condición jurídica alguna. Así ocurre con las disposiciones legales y sus proyectos; con las resoluciones de los órganos jurisdiccionales y parajudiciales; con la expresión de los actos políticos y administrativos de los organismos públicos; con las traducciones de todos estos textos; y con las reproducciones de obras situadas en vías o parajes públicos. O tra cosa es la recopilación de estos materiales y, más aún, del comentario de todo o parte de ello y de su manera de reseñarlo, siempre que presente originalidad suficiente.

Como en toda obra de creación, se puede incorporar al mensaje destinado al medio ciberespacial las simples citas de los títulos o las reproducciones de fragmentos textuales o icónicos, siempre que su extensión sea la que establecen los usos y la buena fe; y que nazcan del carácter de la incorporación y de su finalidad, en especial cuando se trata de obtener un mensaje complejo para fines docentes 0 de investigación.

Del mismo modo, pueden incorporarse con toda libertad trabajos y artículos sobre temas de actualidad publicados previamente en medios de comunicación social, si no se hace constar en éstos de modo expreso la reserva de derechos; y con la cita del autor si aparecieran firmados. Tienen el mismo carácter de reproducibles libremente los discursos pronunciados en los parlamentos o en sesiones de corporaciones públicas; los informes ante los tribunales; y las conferencias, alocuciones, mítines, etcétera, pronunciados en público.

Pueden incorporarse parodias de obras ya difundidas que no presenten riesgos de confusión con la obra parodiada y no infieran daño moral o económico al autor de ésta u obstaculicen la difusión de la creación original.

Sin finalidad lucrativa y con el objetivo de investigación y docencia, puede reproducirse material cuyo autor existe y está protegido cuando el productor sea un museo o una tea de cualquier clase (biblioteca, hemeroteca, cinemateca, etcétera) 
0 archivos de titularidad pública o integrados en instituciones de carácter científico o cultural.

En todos estos casos puede comprobarse que el derecho de autor, en cuanto facultad del derecho a la información, no sufre menoscabo porque va, en cambio, en favor de las tres facultades que componen el derecho comunicativo o de alguna de ellas que corresponde a toda persona según el citado párrafo 1 del artículo 27 de la Declaración Universal de 1948.

\section{OBRAS CON DERECHOS DE AUTOR VIGENTE Y EXIGIBLE}

Cuando la protección legal ampara el derecho del autor es necesaria su licencia para que su creación sea incorporada al mensaje complejo; lo que lleva consigo la voluntad positiva y eficaz de transmisión de las facultades necesarias para hacer jurídicamente normal la incorporación, dando por supuesto el respeto a las facultades morales.

Las obras literarias en su más amplio sentido son incorporables, ya estén expresadas en palabras o símbolos y con independencia del medio en el que están soportadas: papel, película, disquette, CD-rom, Internet o cualquier otro soporte "on line". El mismo régimen siguen las creaciones icónicas.

Las bases de datos se consideran colección protegida siempre que presenten originalidad suficiente en la selección, coordinación o disposición de las materias contenidas en la unidad documental, estén o no integradas por obras protegidas 0 por material no protegido por el derecho de autor, como nombres, direcciones 0 simples hechos. Necesitan, por tanto, autorización y transmisión de facultades. Hay que tener en cuenta que los datos personales están sometidos, además, a un régimen de protección específico que exige autorización de los interesados, siempre guardando respeto a sus derechos naturales, como honor o intimidad. Hay que tener en cuenta también los derechos, patrimoniales o no, de imagen, tanto en su sentido negativo o de respeto al derecho a su no difusión, como en el positivo de derecho a diferentes formas de publicación, como puede ocurrir con los artistas, modelos publicitarios, etcétera.

Los materiales de todos estos tipos admiten varias formas de integración que deben quedar claras en las condiciones de transferencia. La que supone una disposición mayor de la facultad de difusión es la que autoriza a una reproducción total del texto. Si lo que se pretende incorporar es un fragmento, debe quedar perfectamente delimitado. Si es un resumen, la transferencia será necesaria cuando su extensión y detalle dispensen de recurrir a la obra de origen. En este supuesto entran los abstracts que no reproducen la forma del trabajo original, sino que trazan de nuevo su estructura. Lo mismo puede decirse de los títulos de obras que, aunque protegidos legalmente como formando parte del derecho del autor, es posible utilizarlos sin licencia cuando su incorporación tenga un fin exclusivo 
de identificación. En supuestos distintos a los aquí planteados, como el de la obra original transformada, es necesaria la licencia para la utilización o integración con el objeto de poder modificarla y difundirla.

Es indispensable la licencia cuando se trata de obras musicales, sean composiciones completas, con o sin letra, o sean partes que la integran. Cuando se trate de obras mixtas dramático-musicales, como una ópera, la transferencia ha de abarcar no sólo el sonido, sino también el argumento, los diálogos cantados o recitados, la coreografía y, en su caso, los decorados y vestuarios. En estos supuestos, hay que tener en cuenta también los llamados derechos afines por el transferente de la obra principal, si dispone de ellos, o por quien los ostente. Igualmente ha de consentir la persona que sea titular del derecho sobre los arreglos, por ejemplo, para orquestación de obras que no nacieron con la finalidad de ser interpretadas por un conjunto orquestal. Es indiferente el origen de la producción musical, sea la tradicional instrumental, sea la electrónica, obtenida por técnicas de computación; así como su modo de fijación, desde partituras escritas a todo género de soportes susceptibles de autoprogramación.

Es necesaria la autorización para las obras audiovisuales de toda especie, como producciones cinematográficas, televisivas o videográficas, con o sin sonorización incorporada y con independencia de los soportes materiales en que se presenten. Habrá que tener en cuenta la dependencia o independencia, en cada producción, de la imagen y del sonido.

De igual modo es necesaria la autorización en las obras radiofónicas o televisivas, como entrevistas, coloquios, etcétera, ya se aprovechen solamente fragmentos, ya los programas completos.

Para finalizar, es forzosa la autorización de quien tenga los derechos sobre las imágenes fijas, como fotografías que recojan o no obras de arte; ilustraciones, dibujos, grabados; proyectos, planos y diseños; mapas, gráficos e infografías, independientemente de sus derechos industriales.

\section{LA CESIÓN DE LAS FACULTADES NECESARIAS Y SUFICIENTES}

Además de las reglas generales de los contratos y de las específicas que pueden ser aconsejables en cada caso, con tal de que no vayan contra la ley, para que la cesión de las facultades necesarias sea suficiente y eficaz, es preciso acordar un conjunto de cláusulas que, no siendo esenciales, pueden llamarse naturales en relación con la finalidad ciberespacial; o básicas para garantizar la pacífica actividad plurimedia que se puede obtener con los mensajes complejos que se han de difundir.

Así, resulta elemental, aunque puede ser complicado, en ocasiones, la determinación concreta de la obra o de la parte específica que constituye el objeto de la autorización que se persigue; 0 , en su caso, el modo de utilización que se efectua- 
rá de la obra original o de parte de la misma y el soporte en que se hallen para poder realizar la integración. Lo es también determinar la legitimación de la parte cedente, bien sea el autor, su causahabiente o el representante de uno u otro. Pensemos, por ejemplo, en música ambiental cedida por el autor a una agencia distribuidora de composiciones musicales que ha desaparecido. La casuística puede ser múltiple y variada.

Alguna de las condiciones del acuerdo suele entenderse por defecto. Así la duración del contrato; el territorio de explotación; y la exclusividad o no. Si alguna de estas circunstancias no se pacta, suelen entender las legislaciones subsidiariamente que la duración del contrato se extiende a cinco años, pudiéndose establecer prórrogas; el territorio ha de ceñirse a la extensión del país en que se realiza la transmisión o los del mismo idioma o región del globo; y la cesión ha de considerarse no exclusiva.

Las partes gozan de libertad para establecer una remuneración proporcional a los ingresos 0 a los beneficios que obtenga el productor; 0 una remuneración a tanto alzado. En el primer caso hay que fijar el porcentaje de participación, la periodicidad de la entrega de cuentas, las modalidades de liquidación y, en su caso, las posibilidades de auditorías y controles. En el segundo, en algunas legislaciones, se establece una cláusula legal, implícita en los contratos, según la cual si los ingresos son muy superiores a los previstos, se puede revisar la cantidad entregada a tanto alzado, bien porque lo acepte de buen grado el cesionario y haya un acuerdo acerca del incremento, bien porque lo fije el juez, previa declaración de que procede.

Asimismo, se enumeran las facultades cedidas que deben ser estrictamente las necesarias para conseguir las distintas modalidades de explotación, incluso a título gratuito. Lo normal en un producto ciberespacial es que el productor obtenga las facultades de reproducción, de transformación y de difusión de los materiales a integrar. La facultad de reproducción parece fundamental para obtener el mensaje complejo; la de difusión es imprescindible. El proceso de integración puede requerir diferentes formas de incorporación como la fijación en impresora, la digitalización de los materiales, su memorización, la fijación de un soporte a editar, la visualización en pantalla, etcétera, 0 varias de estas formas combinadas que deberán también pactarse.

Este proceso de integración implica que el mensaje original sea adaptado, modificado o transformado en múltiples formas para lo que debe obtenerse la facultad de transformación necesaria para conseguir el encaje en el mensaje ciberespacial, incluidas traducciones; arreglos de una partitura; alteraciones del tono de un sonido; variaciones en un texto; transformación de la apariencia de una figura fija 0 en movimiento, etcétera.

El producto final ciberespacial puede pensarse teóricamente que se obtiene sólo para su disfrute por el productor en su vida privada. Pero no será éste el caso usual. El productor obtiene el mensaje integrado para su difusión por lo que ne- 
cesita que se le atribuya tal facultad sinequa non del derecho de autor. Según el mensaje conjunto que se pretende obtener variará esta forma de difusión; 0 viceversa: por ejemplo, si el medio apto es de autoprogramación o de heteroprogramación. $Y$, según tal forma, procederá difundir y, en su caso, distribuir el producto mediante contratos diferentes: venta, alquiler, préstamo, precario, etcétera. La licencia debe extenderse, en todo caso, a las modalidades que sean esenciales. Según sean estos casos, procederá obtener la licencia para la difusión pública de emisión por ondas o por cable; 0 por exhibición en proyecciones, exposiciones, exámenes de documentos, etcétera; o por la grabación en medios electrónicos para su utilización en computadoras, según los sistemas o plataformas.

En los contratos pueden mencionarse garantías concretas. Por parte del que cede y como simple ejemplo, la facultad de revisión y el veto de las adaptaciones antes de ser utilizadas; o la comprobación de que el nombre del autor original está suficientemente determinado. Por parte del que cede, igual y de manera inexhaustiva, la garantía del goce pacífico por el cesionario del material cedido porque a éste le corresponden las facultades objeto de cesión y no se infringen los derechos de un tercero; o la defensa en caso de que un tercero impugne la difusión del producto ciberespacial obtenido y el resarcimiento de daños en el supuesto de que prevalezca la razón del reclamante.

Finalmente, además de otras condiciones que pueden establecerse con libertad y, como se ha dicho, con la única precaución de que no infrinjan las disposiciones legales 0 , en su caso, las normas de la moral, puede determinarse la ley nacional aplicable al contrato, siempre que no esté predeterminada en el ordenamiento, según el negocio de que se trate y el objeto del mismo. En defecto de esta determinación, suele definirse que se aplicará sucesivamente la ley nacional común de las partes, la ley de residencia habitual común y la ley del lugar de celebración del contrato. Cuando la transmisión de facultades, la incorporación de mensajes o su difusión trasciendan las fronteras, la determinación de la ley aplicable adquiere una singular importancia que hay que someter a los preceptos del Derecho internacional privado.

Las partes son libres para fijar la jurisdicción a la que hay que someter sus litigios y para establecer cláusulas compromisorias de atenimiento a un régimen arbitral.

\section{LA RECEPCIÓN A TRAVÉS DE SATÉLITES}

Puede ocurrir, cada vez con más frecuencia, que los materiales preexistentes protegidos por el derecho de autor vengan a disposición del productor transmitidos por satélites, lo que lleva consigo problemas que pueden trascender de las fronteras de un ordenamiento jurídico, dado que el mensaje originario está protegido en un país y se recibe y se utiliza en otro. 


\section{Invesicaaón Biblictedóǵca V. 12 No. 25 julio/ diciembre de 1998}

Sabido es que, dentro del género de los satélites geoestacionarios, se encuentran los de servicio fijo (SSF) y los de difusión directa (D BS). Los primeros son satélites reflectores que se limitan a poner en contacto dos estaciones, emisora y receptora. Es necesario, después de recibir la señal, retransmitirla a través de una onda radioeléctrica terrestre o de un sistema de cable para hacerla llegar al público en general. Los satélites de difusión directa, en cambio, son los que pueden ser recibidos, a través de antenas parabólicas cadavez de menor tamaño, por los aparatos receptores convencionales, haciéndolos de este modo asequibles a los consumidores finales o sujetos universales. La difusión de los mensajes y, en consecuencia, la efectividad del derecho a la información son así máximas en los satélites de difusión directa.

D esde el punto devista del derecho de autor, uno y otro tipo de satélites plantean problemas diferentes, aunque para operar por ambos sistemas es obligatorio el consentimiento del titular. Este consentimiento se refiere, sin embargo, en losSSF al re ceptor único y le debe capacitar para transmitirlo a los receptores múltiples a quienes, a su vez, distribuye.

En el caso del D BS la transmisión del satélite es ya última en el sentido de que es recogida por cualquiera que disponga del dispositivo técnico adecuado: la autorización no tiene que prever una ulterior transmisión de facultades. Esta regla general del sistema D BS quiebra, en cambio, cuando el receptor es un productor ciberespacial que incorpora la emisión o parte de ella al mensaje complejo. D irectamente o a través de la emisora que conecta con el satélite por medio de una longitud de onda ascendente han de conseguirse la facultad de incorporación, la de modificación, en su caso, y la de difusión necesarias conforme a la casuística variada expuesta.

Por supuesto, cuando las relaciones entre emisor - titular del derecho- y receptor-productor son pacíficas, cabe el acuerdo directo que no vaya en contra de ninguno de los dos ordenamientos que han de ponerse en juego, aun cuando sea para ceder uno en favor de la aplicación del otro. Facilitará el acuerdo en el que en ambos países, o al menos en uno de ellos, existan normas específicas sobre transmisión de mensajes vía satélite.

Cuando la relación no sea tan sencillae, incluso, como vía de solución cómoda acogiéndose a ella, hay que tener en cuenta el régimen convencional supranacional sobre derecho de autor. Pueden existir tratados bilaterales entre las dos potencias implicadas. Pero pueden ambas estar acogidas a diversos convenios multilaterales de los que cabe citar dos como paradigmáticos por el gran número de Estados firmantes de uno y otro: el Convenio de la Unión de Berna parala protección de obras literarias y artísticas de 9 de septiembre de 1886, revisado después en diferentes fechas; y el Convenio Universal de Ginebra de derechos de autor de 6 de septiembre de 1952, también puesto al día posteriormente.

En el caso de uno y otro los privilegios de que gozan los autores incluyen la posibilidad de transmitir las facultades necesarias para constituir el mensaje ciberespacial y para que éste pueda ser difundido, a su vez, no sólo transportado en soportes sólidos distribuibles, sino también en soportes inalámbricos o alámbricos para su te ledifusión. Estas facultades han de ponerse en movimiento siempre que sea necesario, conforme a los supuestos contemplados. 


\section{LA ORIGINALIDAD DEL PRODUCTOR}

En la composición de los mensajes complejos ciberespaciales cabe también la inclusión, en todo o en parte, de elementos originales del productor o sobre los que el productor tiene, a título derivativo, derechos de autor. En tal supuesto, se obvia el sistema de autorizaciones y transferencias de facultades necesarias para disponer del material preexistente al que tienen derecho otras personas. Lo que no deja de presentar problemas, dado que lo normal es que el productor disponga del derecho de autor por el esfuerzo intelectual ajeno que, por diversas causas lícitas, ha venido a su titularidad.

La creación intelectual original se ha podido generar de manera personal por el mismo productor. Será más frecuente producirla por encargo expreso del productor en virtud de un contrato de obra o de servicios. Pero por el mero hecho de la ce lebración de esos contratos no se transmite el derecho de los verdaderos creadores. Es menester que, en virtud del objeto, lo disponga así la ley o que existan cláusulas escritas que acrediten que se ha convenido tal transmisión. Lo primero suele ocurrir en las obras de naturaleza audiovisual en las que las leyes presumen, en exclusiva al productor, cedidas las facultades necesarias para reproducir, difundiry distribuir los mensajes, así como para el doblaje y el subtitulado. Tanto en este caso como en el convenido entre partes, hay que respetar las facultades morales, intransferibles.

Los contratos de obras y servicios pueden concertarse con una persona o con varias. En este segundo supuesto puede darse lugar a la llamada obra en colaboración, aquella en la que intervienen varios autores con contribuciones distinguibles y atribuibles a cada uno, pero cuyas contribuciones constituyen partes inseparables 0 interdependientes en el mensaje final.

Diferente es la obra colectiva: la constituida por la aportación de diferentes autores cuya contribución personal se funde en una creación única y autónoma, para la cual ha sido concebida, sin que sea posible atribuir separadamente a cualquiera de ellos un derecho sobre el conjunto de la obra realizada.

Se considerará, en cambio, obra compuesta a la obra nueva que incorpore una obra preexistente sin la colaboración del autor de estaúltima, sin perjuicio delos derechos que a éste corresponden y de su necesaria autorización, de manera que conserve su independencia, aunque se publique junto con otras, como, por ejemplo, la letra de una canción.

O tra posibilidad, distinta al contrato de obras o servicios es la creación por personal asalariado del productor. El tema de los derechos de autor, en tal supuesto, se regirá por el contrato de trabajo, que ha de otorgarse por escrito. A falta de éste, se presumirá que la facultad de difusión ha sido cedida en exclusiva, pero tan sólo con el alcance necesario para el ejercicio de la actividad habitual del empresario en el momento de la entrega de la obra realizada en virtud de la relación laboral, de modo que el empleador no puede utilizar la obra para un sentido o en forma diferente de lo que se deriva de su objeto social o individual de difundir; o, en su caso, en otro medio propio distinto al que trabaja el creador, aunque pertenezca al empleador.

En todos los supuestos mencionados, las leyes suelen exigir el contrato por escrito y la declaración expresa de la transmisión. Sin embargo, no suelen establecer la 


\section{Investigaaón Biblictedóǵca V. 12 No. 25 julio/ diciembre de 1998}

nulidad del contrato en el que estas condiciones no se cumplan. En algunos casos, se prevé que el defecto del cumplimiento legal se subsane porque las partes puedan compelerse recíprocamente a completar, desde el punto de vista formal, lo establecido sustantivamente, pudiendo acudir al juez si alguna de ellas no se aviene.

Las presunciones, a falta de pacto expreso, se entienden a favor del productor por aplicación del principio indubioproinformatione por el principio de generalidad que rige los mensajes; y por la comprensión de la facultad de difusión como integrante del conjunto de facultades que constituyen el derecho a la información. Se entiende siempre que la difusión de esos mensajes sea la que persiguela actividad del productory por aquellos medios a través de los cuales el productor habitualmente difunde, bien porque constituye su objeto social si se trata de una empresa, bien porque sea una actividad habitual si el productor es una persona física. En cambio, cuando la falta de puntualización en los convenios o sus deficiencias de claridad originan dudas o litigios en los que no esté en juego la difusión, el principio aplicable es, en cambio, indulioproaudtore, más que por considerarlo la parte débil del contrato, por ser la causa eficiente de los mensajes informativos de todo tipo.

\section{LAS CARACT ERÍST ICAS CIBERESPA CIALES}

En la comunicación ciberespacial, además de los mensajes, puede haber otros objetos protegidos por el derecho de autor, como la especial estructura de la expresión, la indización, el thesauro, el programa de computadora específicos para elaborar la estructura y el consiguiente uso de ventanas, fondos, íconos y paneles de control que componen cada uno de ellos.

La problemática que puede presentarse por el juego de todos o de parte de estos caracteres ha de tener unas soluciones acordes o análogas con lo ya expuesto para el mensaje, teniendo en cuenta al titular de los derechos de autor o análogos protegidos y que se utilicen porque preexisten a su utilización por el productor o porque él mismo los crea o los asumey los modula para el buen fin dela difusión informativa.

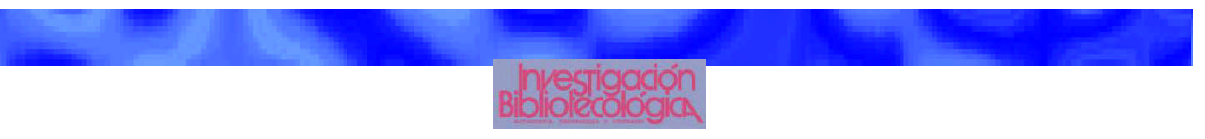

